\title{
Productivity Improvement or Signal Transmission: Different Paths of Education Returns
}

\author{
Liu Jiansheng \\ Central University of Finance and Economics \\ School of Economics \\ China
}

\begin{abstract}
Individual income is positively correlated with education level, which has been confirmed by various empirical analyses worldwide. However, the interpretation of this positive correlation in the literature is different. According to the theory of human capital represented by Jacob Mincer, the higher the individual's education level is, the higher the income is, because the individual's productivity is improved in the process of receiving education. The signal transmission theory represented by Michael spencer is considered to be the education will not increase the productivity of the individual, but the corresponding diploma in education process as a "signal" delivered the individual inherent productivity levels, so as to make the employer will give high degrees higher wages in the labor market. In this paper, the education system is combined to estimate the return rate of education in China, and the devotion of production theory and signal transmission theory in the whole education. For this reason, this paper selected and screened 23749 data of 12 provinces and cities from the Chinese health and nutrition survey (CHNS) website for mixed OLS regression analysis. The results show that the signaling function of college diploma and college diploma is very strong under China's education system. The value of a high school diploma depends on competitors for the job.
\end{abstract}

Keywords: return rate of education, production function, signal transmission

\section{The Introduction}

So far, research for the problem of education returns is quite rich, almost all the research and analysis show that personal income and education level are present positive correlation, namely the individual by the higher education level, the higher income will, in spite of personal income at the same time also will be affected by many other factors (such as gender, family background, race, etc.). But in terms of the relationship between income and education level, what is the real reason behind the increase in income brought by the improvement of education level?

There are two main arguments for answering this question in the current academic world: one is the theory of productivity growth, represented by economists such as Gary s. becker and Jacob Mincer. The theory of the economists thinks that the productivity of individual will increase in the process of accepting education. Highly educated have higher income than non-graduates, the main reason is the high degree in the education process learn more knowledge, improve the labor productivity and deserve higher income. A very different view comes from the signaling theory represented by Michael Spence. According to the signaling theory, individual labor productivity is an internal quality affected by many factors (such as family environment, race, talent, etc.), while education has little impact on productivity, education only plays the role of reflecting individual inherent productivity in the whole process. Therefore, the high income source of highly educated people is not because of the improvement of their production capacity during the learning process, but employers can only regard the education level as a reflection of one's inherent labor productivity in the case of information asymmetry. That is to say, highly educated people send signals to employers that they are highly productive, thus encouraging employers to pay higher wages to hire highly educated people. This is also the reason why the society presents a phenomenon of high income for the highly educated.

So is the theory of production or the theory of signal transmission more tenable in a country that places great emphasis on diplomas? Under China's education system, which is more important, the productivity effect or the signalling effect? 
Based on this consideration, this paper attempts to achieve the following two purposes: one is to explore whether the substantial source of high income is the result of productivity improvement or signal transmission. The second is if both factors are at work, which one is more influential.

\section{Related Theories and Literature Review}

The literature on the real growth of education returns falls into two categories: one is based on Jacob Mincer's theory of productivity growth. The other is largely based on Michael Spence's signalling theory.

\subsection{Related Theories}

\subsubsection{Production Theory}

Jacob Mincer summarized the ideas of his predecessors in paper 《the investment of human capital and personal income distribution》 in 1958, pointed out that "the personal income is positive correlation with training time (replace with the year of the education), but inverted" $U$ "type" with ages, and used the method of empirical analysis to verify this conclusion. In 1974, Mincer further proposed the basic formula of mincer education income function in his book 《school, experience, and earning》: $\ln Y=\alpha_{0}+\alpha_{1} E d u+\alpha_{2} \operatorname{Exp}+\alpha_{3} \operatorname{Exp}^{2}+v$ Where, ln $Y$ refers to the natural logarithm of income, $Y$ refers to personal income, $E d u$ represents the years of receiving education, Exp refers to the years of working, denoting personal work experience, $v$ denotes the error term, $\boldsymbol{\alpha}_{1}$, $\alpha_{2}$, and $\alpha_{3}$ respectively denotes the coefficient. This formula highly summarizes the education return proposed by Mincer in his paper 《human capital investment and personal income distribution》 which is also accepted by most economists. Later, economists also use the basic formula of Mincer to estimate the rate of return of education.

However, the factors affecting personal income are not only affected by education level and personal work experience, but also influenced by gender, work unit and province. Therefore, in most cases, we will use the Mincer wage equation after the control variable is added:

$$
\ln Y=\alpha_{0}+\alpha_{1} E d u+\alpha_{2} \operatorname{Exp}+\alpha_{3} \operatorname{Exp}^{2}+\sum_{j} \lambda_{j} x_{j}+v
$$

Where, $x_{j}$ is the related control variable, and $\lambda_{j}$ represents the regression coefficient of the control variable.

\subsubsection{Signal Transmission Theory}

The signal transmission theory, its iconic study characters mainly includes K. Arrow, L. Thurow, J.E.Stiglitz, D. Spence and others, they point out the education is only a means of personal transmitting through access to higher education diploma in the employment market, employers judge inherent capacity for employees by judging the education level of employees, so as to achieve balance between wages and education.

Signalling theorists argue that there is screening theory in the Labor market, that Labor productivity is an intrinsic quality that is affected by many factors (family environment, personal experience, talent, etc.) and that education has little impact on it. Education only serves as a signal to reflect the inherent labor productivity of individuals, and the actual productivity of employees did not increase in the process of receiving education. The main reason why employers pay higher wages to people with higher education levels is that employers are more likely to consider themselves highly competent. Since the labor market is an information asymmetric market, employers can only take the education level as the signal of a person's labor productivity. Namely, the signal theory explains the influence of education on individual income through "education-receiving diploma-transmitting signal -increasing the income".

\subsection{Literature Review}

In fact, before Jacob Mincer (1958) proposed the theory that the productivity increase of individuals in the process of receiving education is the reason to have high income in the future, many economists (mainly western economists) had studied human capital investment and education return. Pigou (1932), a famous British economist, pointed out that "the distribution of income and individual capacity are not mutually compatible individual capacity is normally distributed, while the distribution of income is seriously skewed to the right". The problem (or paradox) Pigou pointed out has since been solved by many economists using various economic methods. 
One of the iconic figures is Friedman (1957), who brought personal preferences into the model, arguing that differences in psychological risk preferences were one of the reasons why rational economic men differed in their education investment and job choice. Friedman's theory has been accepted by many economists.

Since the establishment of new China, especially after the reform and open, some scholars began to pay attention to China's education rate of return. Its research on education return in China covers a wide range of aspects, including not only the overall level of education return, but also the trend of education return, as well as the regional differences in education return in China and other aspects.

In terms of research on the overall level of education returns in China, Jamison and Gaag (1987) had calculated the rate of education returns in urban and rural areas based on household survey data in Anhui province. In addition, Byron and Manamoto (1990) et al. also estimated the yield rate of Mincer education based on the citizens of Nanjing, China. In the past 20 years, many Chinese scholars have also carried out the research on education yield rate estimation in China, and perfected the localization study of Mincer income equation. For example, li Shi and li Wenbin (1994) obtained education individual return rate of only 3.7\% in China in 1988 with the help of Mincer wage equation. Li (2003) estimated that education had a return of $5.4 \%$ based on the survey data of urban residents in 11 provinces and cities in 1995.

According to the trend of education returns in China, some famous studies have been conducted: li Shi and Ding Sai (2003) used the data of Chinese urban household sample survey (CHIP) from 1990 to 1999 to estimate the education returns, and concluded that the urban education returns were $2.4 \%$ in $1990,4.9 \%$ in 1995 , and increased to $8.1 \%$ in 1999. According to the CHNS survey data, Qi Liangshu (2005) also used the Mincer wage equation to find that the education rate of return decreased from the late 1980s to the early 1990s, and only increased after 1993. The education rate of return in 1958, 1990, 1992, 1996 and 1999 was $4.56 \%, 2.56 \%, 2.87 \%, 5.39 \%$ and $6.4 \%$ respectively.

The existence of regional differences will also lead to education return differences. Li Shi and li Wenbin (1994) find that the rate of return of urban individual education was nearly 2 percentage points higher than that of rural individual educationby estimating national data in 1988. HouFengyun (2004) estimated the return rate of education in rural areas was $3.66 \%$, and the return rate of education in urban areas was nearly 6 percentage points higher than that in rural areas, according to the results of typical survey data of 15 provinces and autonomous regions in China. Based on the data of Chinese health and nutrition survey, ZhongFuning and Liu Hua (2007) found that when both personal income and education return were on the rise, the income gap between different education levels and education return were on the rise.

The most famous theory of signal transmission is the "sheepskin effect" of education obtained by "H-S" method. That is to say, after verification by Hungerford and Solon in 1987, education benefit returns were found to be discontinuous. They found that the return on a diploma year was significantly higher than in other years, which they attributed to diploma. $\mathrm{H}$ and $\mathrm{S}$ consider this to be a function of signal transmission. For the shortcomings of "H-S" method, scholars such as Jaeger and Page (1996) introduced education years into the equation on the basis of "H-S" method, and finally found that the sheepskin effect of American high school and college education was significant.

In addition, some economists have compared populations by dividing them into unfiltered and unfiltered groups. Wopin (1977) found that education had both signal transmission and production function. Later, this test method was called Wopin test. According to Riley (1979), different occupations have different signaling effects. Through comparison between screened occupations and non-screened occupations, the study found that non-screened occupations had higher starting salary and lower average education according to data related to 113 occupations in the United States. Later this test was also called Riley test.

\section{Model and Data}

\subsection{MeasurementModel}

Based on previous research, we know that there are many factors affecting a person's salary and income level, including work experience, age, gender, job attributes and other factors besides education level. Based on this, the models established in this paper are mainly as follows:

$\lg$ hrwage $=\beta_{1}$ schooly $+\beta_{2} \exp +\beta_{3} \exp ^{2}+i . g e n d e r+i . u r b a n+i . p r o v+i . w a v e+i . j o b+i . w r k u n i t(1)$ 


\section{$\lg$ hrwage $=i . \mathrm{a} 11+\beta_{1} \exp +\beta_{2} \exp ^{2}+i . g e n d e r+i . u r b a n+i . p r o v+i . w a v e+i . j o b+i . w r k u n i t(2)$}

The relevant variables of the above two models are explained as follows:

1. Both models take"In hrwage"as explained variable,"In hrwage"as the logarithm of an individual's hourly wage.

2. The first measurement model represents "schooly"as the education level and the second model represents"a11"as the education level. Where "school "refers to the single individual's education years, which is a continuous variable, and its regression coefficient" $\beta_{1}$ "mean each additional education year, the individual's income level growth percentage. However, we use the expression"a11"for the highest education level of a person. For example, when a person's education years are 12 (schooly=12), we use the expression"a11"for a senior student education level. In other words, I transformed the education system in China, which was originally a continuous variable "schooly", into a dummy variable which is expressed by"a11", and then made a regression.

3. We know that there are many factors affecting a person's wage income level. In order to obtain the correlation coefficient, we can describe the impact of education level on wage as accurately as possible. Where "exp" and "exp" "respectively represent the working years of individuals and the square of working years;"gender"refer to men or women; "urban"refers to whether an individual's household registration type is urban or rural; "prov" represents where the labor is in; "wave" represents the year of data collection; "job" means the type of personal work; "wrkunit" represents the attributes of an individual's work unit. Some of these variables are preceded" $i$ " by the process of regression in which the corresponding variables are treated as dummy variables.

\subsection{Data and Sources}

The data of this paper mainly comes from the Chinese health and nutrition survey (CHNS) website, and the "provincial minimum wage standard" and "provincial consumer price index" issued by the national bureau of statistics are used to calculate personal hourly wage. Most of the variables involved in the above model are directly given in the survey data, and only some individual variables, such as"ln hrwage", "a11" and "exp" need to be calculated. The above three variables are explained as follows:

1. "In hrwage"refers to the logarithm of an individual's hourly wage. It screened outindividual who earns $50 \%$ less than the minimum wage standard in his or her province; Then, according to the "provincial consumer price index" released by the national bureau of statistics, the wage level is used to convert all the different annual wages into the actual wage level based on the year 2000. Finally, calculate the hourly wage according to the number of working hours of each interviewee and obtain the logarithm.

2. "a11" is obtained according to the variable "schooly". Since "a11" is treated as a dummy variable in the regression, the wage income difference between different education degrees can be obtained by observing a series of "a11"coefficients.

3. We know that for individuals, the influence of working years on their salary is also obvious. Therefore, this paper adopts the internationally accepted method to calculate the working years of an individual, namely "working years = survey age - education years -6", and denotes it by“exp".

\section{Empirical Results}

Judging from the reality of China's labor market, junior high school diploma has little effect. Therefore, this empirical analysis mainly explores the role of the signaling functions of high school diploma, associate degree and college degree.

\subsection{Productivity Promotion Effect}

\section{$\lg$ hrwage $=\beta_{1}$ schooly $+\beta_{2} \exp +\beta_{3} \exp ^{2}+i . g e n d e r+i . u r b a n+i . p r o v+i . w a v e+i . j o b+i . w r k u n i t$}

We know that without considering the signaling effect of a person's diploma, the productivity improvement effect is expressed in terms of the percentage increase in hourly wages that would result from each additional year of receiving education.

From the model (1), we know the regression coefficient $\beta_{1}$ represents the percentage increase in personal income for each additional year of receiving education. 
In other words, we can use $\beta_{1}$ to represent the productivity gains of individuals in the education process. But the premise is that we have to remove all data related to the year of graduation to ensure that there is no diploma signalling function.

But to measure the productivity gains, it is necessary to make a hypothesis about the productivity gains in education every year. Here, the paper assumes that individuals receive the same productivity boost for each additional year of education. Although this assumption has certain limitations, it is reasonable: although for different individuals, every extra year of education brings different productivity improvement effects, some people have great productivity improvement effects in primary school, some people are in junior high school, and some people are in senior high school or junior college. So when we add all these people together, we can assume that the productivity gains from each additional year of education are the same.

Based on this hypothesis, we can measure the productivity improvement effect of different groups. This paper divides the population into three categories: those with high school diplomas are the first group; A second group with an associate degree; People with college degrees are in the third group. Then the productivity improvement effect of each group was measured separately. The following table is the regression results obtained by using OLS regression.

Table 1:

\begin{tabular}{|c|c|c|c|}
\hline & High school & Associate degree & College degree \\
\hline & ln hrwage & ln hrwage & ln hrwage \\
\hline \multirow[t]{2}{*}{ schooly } & $0.00464^{* *}$ & $0.0119^{* * *}$ & $0.0178^{* * *}$ \\
\hline & $(2.69)$ & $(8.90)$ & (12.77) \\
\hline \multirow[t]{2}{*}{$\exp$} & $0.0156^{* *}$ & $0.0171^{* *}$ & $0.0174^{* * *}$ \\
\hline & $(6.34)$ & $(8.53)$ & $(8.92)$ \\
\hline \multirow[t]{2}{*}{$\exp ^{2}$} & $-0.000233^{* * *}$ & $-0.000246^{* * *}$ & $-0.000263^{* * *}$ \\
\hline & $(-5.50)$ & $(-6.86)$ & $(-7.43)$ \\
\hline \multirow[t]{2}{*}{ gender } & $0.208^{* * *}$ & $0.185^{* * *}$ & $0.185^{* * *}$ \\
\hline & $(16.03)$ & $(15.69)$ & $(15.58)$ \\
\hline \multirow[t]{2}{*}{ urban } & 0.00789 & 0.0209 & $0.0282^{*}$ \\
\hline & $(0.55)$ & $(1.60)$ & $(2.16)$ \\
\hline Control prov & yes & yes & yes \\
\hline Control wave & yes & yes & yes \\
\hline Control job & yes & yes & yes \\
\hline Control wrkunit & yes & yes & yes \\
\hline \multirow[t]{2}{*}{ cons } & $2.009^{* * *}$ & $2.169^{* * *}$ & $2.492^{* * *}$ \\
\hline & $(5.61)$ & $(5.43)$ & $(10.50)$ \\
\hline$N$ & 7909 & 9122 & 9591 \\
\hline
\end{tabular}

T statistics in parentheses

$* \mathrm{p}<0.05, * * \mathrm{p}<0.01, * * * \mathrm{p}<0.001$

Before the analysis of the regression results, it should be noted that during the regression in this paper, in order to avoid the effect of signal transmission, the data of the year of graduation was discarded. That is, when measuring the productivity improvement effect of people with a high school diploma, information about the year of graduation and people with a high school above education (schooly=9,12,13,14,15,16) is omitted. When measuring the productivity gains of people with an associate's degree, information about the year of graduation and those who had a education level above associate's degree (schooly $=9,12,15,16$ ) was omitted. When measuring the productivity gains of those with a college degree, information about the year of graduation and those with a education level above college degree (schooly=9, 12, 16) were excluded.

Since the data in the regression is all data information that is subject to education level in the year of graduation, the result is completely without the effect of signal transfer function. We also assumed that each additional year of schooling would have the same effect on productivity. So we believe that the coefficients of "schooly" are skewed by productivity gains after controlling for other related variables. 
From the analysis of regression results, it can be concluded that:

1. For those with a high school diploma, they received education for one more year, and their wage income increased by $0.464 \%$. That is to say, the effect of wage income change brought by productivity improvement of this group is $0.464 \%$.

2. For those with associate degree, they received education for one more year, and their wage income increased by $1.19 \%$.

3. For those with a college degree, they received education for one more year, and the wage income increased by $1.78 \%$, that is, the change of wage income caused by the productivity improvement of such people is $1.78 \%$.

\subsection{Signal Transmission Effect}

Using model (1), we know the effect of productivity improvement on individual wage income. So in order to measure the magnitude of signal transfer function, we need to use model (2).

\section{$\lg$ hrwage $=i . \mathrm{a} 11+\beta_{1} \exp +\beta_{2} \exp ^{2}+i . g e n d e r+i . u r b a n+i . p r o v+i . w a v e+i . j o b+i . w r k u n i t$}

In this model, we plug the education level into the equation as a dummy variable a11, and the difference is, by looking at the coefficients, we can see the difference in wages and incomes between education levels. This gives us a way to see how the salaries of the graduate vary compared to undergraduate.

Similarly, according to the above group, mixed OLS regression was conducted on the data of each group, and the regression results were as follows:

Table 2.

\begin{tabular}{|l|l|l|l|l|l|}
\hline & High school & & Associate degree & & College degree \\
\hline & $\lg$ hrwage & & $\lg$ hrwage & & $\lg$ hrwage \\
\hline Senior 1 & 0.0520 & College 1 & $0.228^{* *}$ & Sophomore & $0.328^{* * *}$ \\
\hline & $(1.18)$ & & $(3.16)$ & & $(9.48)$ \\
\hline Senior 2 & $0.0636^{* * *}$ & College 2 & $0.219^{* * *}$ & Junior & $0.409^{* * *}$ \\
\hline & $(3.31)$ & & $(11.03)$ & & $(19.77)$ \\
\hline Senior 3 & $0.109^{* * *}$ & College 3 & $0.347^{* * *}$ & Senior & $0.552^{* * *}$ \\
\hline & $(6.81)$ & & $(15.63)$ & & $(20.48)$ \\
\hline cons & $2.597^{* * *}$ & cons & $2.502^{* * *}$ & cons & $2.571^{* * *}$ \\
\hline & $(17.61)$ & & $(18.93)$ & & $(21.81)$ \\
\hline$N$ & 18926 & $N$ & 21342 & $N$ & 21487 \\
\hline
\end{tabular}

T statistics in parentheses

$* \mathrm{p}<0.05, * * \mathrm{p}<0.01, * * * \mathrm{p}<0.001$

It can be seen from the regression results that:

1. Measure the signaling effect of high school diploma.

The regression results showed that the average hourly wage increased by $4.27 \%$ for those who completed their third year of high school (with a high school diploma) compared to those who completed only their second year of high school (without a high school diploma). We already know that for people with only high school or below, their productivity boost is $0.464 \%$. So people with high school diplomas have a signal of $3.806 \%$. Therefore, in high school education, the impact of production function on education return is $10.87 \%$, and that of signal function is $89.13 \%$.

2. Measure the signaling effect of college diploma.

By the same token, people with associate's degrees earned $10.5 \%$ more per hour than those with two year education (without associate's degrees) in college. This is the result of a combination of signalling and productivity gains. It is already known that the productivity increase is $1.19 \%$ from college level 2 to college level 3. Therefore, the signaling effect of college diploma is $9.31 \%$.In other words, during the whole education return process, the impact of production function was $11.33 \%$, while the impact of signal transmission function was $88.67 \%$. 3. Measure the signaling effects of a college degree.

The same is true for people who choose to go to university after high school. It can be seen from the chart that those who completed their fourth year of university (with a bachelor degree) earned $10.15 \%$ more than those who completed their third year of university (without a bachelor degree). The productivity boost from three to four universities was $1.78 \%$. The signaling effect of a bachelor degree was $8.37 \%$. 
Therefore, in university education, the influence of production function on education return is $17.54 \%$, and the influence of signal function is $82.46 \%$.

\section{Conclusions and Policy Recommendations}

The main content of this part is to draw the main conclusions of this paper based on the above research results and give corresponding policy recommendations.

\subsection{Main Conclusions}

Through regression analysis and correlation calculation, the main conclusions of this paper include the following aspects:

1. As education years increase, the salary level of individuals shows an upward trend. Whether they graduated from high school, college or university, after controlling the influence of working years, gender, provinces and cities, occupation, work units and other factors on their income, individuals were positively affected by education years on their future wage income.

2. In China's labor market, education returns are realized mainly through two channels, namely productive function and signal transmission function. After excluding the influence of gender, occupation, working years and other factors on the salary, the average salary of each person in the year of graduation is always higher than the fitting level. This suggests that signalling works, that these people can use their diplomas to send a signal in the Labor market for a higher-paying job. In addition, from the regression results where all the data of graduation year are excluded,it can be seen that the individual's education years and salary income are still positively correlated, so education returns should also be achieved through productive function.

3. In China's labor market, the signaling function of diploma is far greater than that of productivity improvement. From the analysis of the results, whether it is a high school diploma or an associate degree or a college diploma, their signaling functions are particularly strong. It can be seen that in a country like China, it is crucial to have a diploma.

4. The signaling function of high school diploma is significantly weaker than that of associate degree and college diploma. But a high school diploma also serves as a signalling function when it comes to competing with those less qualified than themselves.

5.Not everyone who has received education will be paid more than anyone who has not received education (illiterate). From the regression results, we can see that if the level of education is the first year of high school or lower, their hourly wage level is not significantly different from that of the illiterate group. Only when an individual's education level reaches the level of second year of high school or above will there be a difference in salary income between individuals who have not received any education.

\subsection{Policy Recommendations}

Based on the above conclusions and the practical problems in China, this paper mainly puts forward the following policy suggestions:

1. Pay attention to the positive effect of education on income, and encourage families or individuals to invest on education. The estimated results of this paper show that as individuals' education years increase, their salary level will also increase. Therefore, individuals should be encouraged to invest in education, and the government should increase funding support for education so that more people can accept education. This is conducive to the increase of people's future income, so that their personal or family life can be more secure.

2. The government should continue to increase investment in basic education, and individuals should strive to accept higher education on the basis of 12-year education. From the analysis results, the return level of basic education is significantly lower than that of higher education. Therefore, the government should continue to pay attention to the input of basic education, and may consider upgrading the 9-year obligation education to 12-year obligation education. At the same time, if an individual wants to gain an advantage in the labor market, it is far from enough to fulfill the 9-year obligation of education.

3. Pay attention to the improvement of human capital and guide enterprises to reduce dependence on diploma. From the above analysis and discussion, we can easily see that China is indeed a country that attaches great importance to diploma. The effect of signaling function is significant, namely the sheepskin effect of diploma is too serious. Therefore, enterprises should be guided to gradually reduce the dependence on the diploma, and judge of employees from all aspects of the quality of personnel. 


\section{References}

Becker. Human Capital Theory [M]. Beijing: Peking University Press, 1987: P25-60

Jacob Mincer. Investment in Human Capital and Personal Income Distribution.The Journal of Political Economy, Vol. 66, No. 4 (Aug., 1958), pp. 281-302.

Michael Spence. Job Market Signaling.Quarterly Journal of Economics, 1973.

A. C. Pigou, The Economics of Welfare (London: Macmillan \& Co., Ltd., 1932), p.648.

M. Friedman, "Choice, Chance, and the Personal Distribution of Income," Journal of Political Economy, LXI (August, 1953), 277-90.

Jamison D. J. V. Gag. Education and Earnings in the People's Republic of China [J]. Economics of Education Review, 1987 (2): 161-166.

Byron, Raymond, Evelyn Q. Manaloto. Return to Schooling in China [J]. Economic Development and Cultural Change, 1990 (38): 783-796.

Li Shi, Li Wenbin. Research on Personal Rate of Return of China's Education Investment, Zhao Renwei and Other Editors, "Research on Income Distribution of Chinese Residents" [M]. Beijing: China Science Press, 1994: 165-208

Pan Zhiyong. Research on the return and source of urban education in China.Master's thesis. 2012.

Mincer J. Human capital and earnings [M]. Wealth, Income and Inquiry. New York: NBER.1980.

Spence-A. Michael. Signaling in Retrospect and the informational Structure of Market [J]. American Economic Review, 1975(3): 434-459

Li, Y. Luo. Human Reporting Errors, Ability Heterogeneity and Returns to Schooling in China [J]. Pacific Economic Review, 2004(9): 191-207.

Li Shi, Ding Sai. The long-term trend of urban education return rate in China [J], Chinese Social Sciences, 2005 (2): 61-72.

Qi Liangshu, The Influence of Labor Wage System in the State-owned Sector on the Rate of Return to Education - An Empirical Study of the Rate of Return to Urban Education in China from 1988 to 1999[J]. Economic Research, 2005 (4): 19-25,

HouFengyun. Research on the Rate of Return of Human Capital in China's Cities and Towns[J].Journal of Shandong University,2005 (2); 21-32.

Zhong Yuning, Liu Hua. An Empirical Study on the Return Rate of Urban Education in China and Its Structural Changes[J]. China Population Science, 2007(4): 34-41. 